\title{
Erratum to: Comparing the in vivo sonodynamic effects of dual- and single-frequency ultrasound in breast adenocarcinoma
}

\author{
Mahboobeh Alamolhoda • Manijhe Mokhtari-Dizaji • \\ Amir Hoshang Barati · Hadi Hasanzadeh
}

Published online: 8 August 2012

(C) The Japan Society of Ultrasonics in Medicine 2012

Erratum to: J Med Ultrasonics (2012) 39:115-125

DOI 10.1007/s10396-012-0348-9

In the above-cited article, the name of the affiliated university of the author Hadi Hasanzadeh was given as Semnan Medical Sciences University. The university name should be correctly shown as Semnan University of Medical Sciences. The name of the affiliated university of the author Amir Hoshang Barati was given as Kurdistan Medical Sciences University. The university name should be correctly shown as Kurdistan University of Medical Sciences.

The online version of the original article can be found under doi: 10.1007/s10396-012-0348-9.

M. Alamolhoda $\cdot$ M. Mokhtari-Dizaji $(\bowtie)$

Department of Medical Physics, Tarbiat Modares University,

P.O. Box: 14115-133, Tehran, Iran

e-mail: mokhtarm@modares.ac.ir

A. H. Barati

Medical Physics Department, Kurdistan University

of Medical Sciences, Sanandaj, Iran

H. Hasanzadeh

Medical Physics Department,

Semnan University of Medical Sciences,

Semnan, Iran 